\title{
PRESS PLAY TO START: GAMES NA FORMAÇÃO DE PROFESSORES DE LÍNGUA INGLESA
}

\author{
Michely Gomes AvelaR ${ }^{1}$ \\ ORCID: 0000-0003-4148-5692 \\ Carla Conti de Freitas ${ }^{2}$ \\ ORCID: 0000-0002-7217-1664
}

Mestra em Língua, Literatura e Interculturalidade, POSLLI/UEG (2019); Graduada em Letras Português Inglês, PUC GO (2012). Participa do Grupo de Pesquisa do CNPQ Rede Cerrado de Formação Crítica de Professoras/es de Línguas e do Projeto Nacional de Letramentos: Linguagem, Cultura, Educação e Tecnologia, da Universidade de São Paulo e do grupo de pesquisa GEFOPLE e a pesquisa Multiletramentos na formação de professores de línguas, da Universidade Estadual de Goiás.

2 Doutora em Politicas Públicas, Estratégia e Desenvolvimento, UFRJ/UEG, (2013) e Pós-Doutorado na Faculdade de Letras da Universidade do Porto (2014); Mestra em Letras e Linguística pela Universidade Federal de Goiás (2003); Especialista em Psicopedagogia, Avaliação Institucional e Docência Universitária e Graduada em Letras Português Inglês (1995). Atua como Docente e Diretora do Câmpus Inhumas da Universidade Estadual de Goiás e docente do Programa de Pós-graduação Stricto Sensu em Língua, Literatura e Interculturalidade. Coordena o grupo de pesquisa GEFOPLE e a pesquisa Multiletramentos na formação de professores de línguas, da Universidade Estadual de Goiás, participa do Grupo de Pesquisa do CNPQ Rede Cerrado de Formação Crítica de Professoras/es de Línguas e do Projeto Nacional de Letramentos: Linguagem, Cultura, Educação e Tecnologia, da Universidade de São Paulo. 
Resumo: Este artigo tem como objetivo apresentar e discutir a ação de extensão denominada Jogos digitais no ensino de língua inglesa: práticas de (multi)letramentos, realizada com professores de língua inglesa em formação. A ação propôs experiências com os games na formação inicial e continuada de professores de língua inglesa propiciando espaços para (re) pensar as práticas de linguagem a partir da cibercultura. As atividades foram desenvolvidas em uma universidade pública no interior do estado de Goiás, entre os meses de abril e junho de 2019 e as análises apontam para a necessidade de discussão e reflexão sobre as ações de extensão para e na formação de professores de línguas.

Palavras-chave: Extensão. Formação de professores de língua inglesa. Games. Multiletramentos.

\section{PRESS PLAY TO START: GAMES IN ENGLISH LANGUAGE EDUCATION}

Abstract: The present proposal brings forward notes about an extension action called Digital Games in English Language Teaching: (multi) literacy practices, performed as English language teachers education. The extension action proposed experiences with games in the English language teachers programm providing spaces to (re)think cyberculture language practices. The activities were developed at a public university in Goiás' inland city, between April and June 2019 and it helps us to understand the relevance of extension actions in language teachers' education.

Keywords: Extension action. English teacher education. Games. Multiliteracies

\section{PRESS PLAY TO START: GAMES EN LA FORMACIÓN DE PROFESORES DE LENGUA INGLESA"}

Resumen: Este estudio tuvo como objetivo presentar la acción de extensión Juegos digitales en la enseñanza del idioma inglés: prácticas (multi)literacidad, realizadas como profesores de inglés en la capacitación. La acción de extensión propuso experiencias con juegos en la educación inicial y continua de profesores de inglés que proporcionan espacios para (re)pensar las prácticas lingüísticas desde la cibercultura. Las actividades se desarrollaron en una universidad pública en el interior del estado de Goiás, entre Abril y junio de 2019y los análisis apuntan a la necesidad de la discusión y la reflexión sobre acciones de extensión para y en la formación de profesores de idiomas.

Palabras claves: Acción de extensión. Formación de profesores de inglés. Juegos digitales. 


\section{PARA INÍCIO DE CONVERSA...}

As práticas de linguagem têm se modificado ao longo do tempo com as novas possibilidades advindas da cibercultura. As tecnologias digitais de informação e comunicação (TDIC) permitem que os interlocutores interajam por meio de múltiplas semioses, assim, nas interações digitais podemos usar a linguagem oral, escrita, imagens estáticas ou em movimento, gestos, áudios, dentre outras.

As novas tecnologias, aplicativos, ferramentas e dispositivos viabilizaram e intensificaram novas possibilidades de textos/discursos - hipertextos, multimídia e, depois, hipermídia que, por seu turno, ampliaram a multissemiose ou multimodalidade dos próprios textos/ discursos, passando a requisitar novos (multi)letramentos. (ROJO; MOURA, 2019, p.26)

Rojo e Moura (2019) destacam que nossa relação com essas novas formas de comunicação requisitam "novos (multi)letramentos", ou seja, outros modos de enunciar e comunicar que são cada vez mais plurais e que envolvem uma diversidade de meios e modos de lidar com a linguagem.

Beavis (2014) destaca que os games são textos que fazem parte da cultura popular, misturam imagens e palavras a outros elementos e reposicionam os seus interagentes como leitores, escritores, interpretes e criadores. Para lê-los - ou jogá-los - são necessários multiletramentos, uma vez que eles vão além da escrita verbal, eles requerem a interpretação de diferentes sistemas de símbolos, imagens, sons, cores, movimentos, dentre outros (BEAVIS, 2014).

Nessa perspectiva, é indispensável que os cursos de formação de professores de línguas considerem estas práticas de linguagem para instigar novos olhares que não se restrinjam às tecnologias enquanto instrumento ou ferramenta de ensino. Requer, portanto, compreender que urge novas formas de se pensar no processo de ensino e aprendizagem que considerem as modalidades de linguagem advindas pelo contexto digital. A comunicação escrita não é única que importa em um sistema comunicacional, as imagens, os gráficos, os símbolos, os sons, os movimentos também são relevantes e significativos (GEE, 2003). Portanto, é preciso propiciar aos professores de língua inglesa uma formação crítica, que considere as multiplicidades de cultura e de linguagem que emergem das novas tecnologias.

Em 2017, realizamos uma pesquisa com discentes do curso de Letras de uma universidade pública situada no interior do estado de Goiás. Na pesquisa evidenciamos que apesar destes discentes utilizarem diariamente diferenciados recursos tecnológicos em suas atividades pessoais - tais como para comunicar, entreter, trabalhar e estudar - e reconhecerem o potencial para o processo de 
ensino-aprendizagem, as tecnologias não eram regularmente utilizadas no contexto escolar (AVELAR, FREITAS, LOPES, 2018). Identificamos que o curso de Letras não viabiliza aos futuros professores de línguas uma formação tecnológica ou que desenvolva percepções para as novas formas de ler, escrever e comunicar considerando a cibercultura (FREITAS, 2019), uma vez que em sua matriz curricular há oferta de uma única disciplina de núcleo específico relacionada à tecnologia e não há evidências desta formação em outras disciplinas que propicie um olhar crítico para as tecnologias do ponto de vista da linguagem. $\mathrm{O}$ curso oferece uma disciplina optativa relacionada à tecnologia, entretanto, não garante oferta a todos e também não contemplam as especificidades da formação profissional do professor de língua inglesa. Conforme identificamos,

apesar de considerar essencial que o profissional de Letras perceba as potencialidades das novas tecnologias, há de se destacar que os cursos de Letras não adequaram seus currículos a realidade sendo que as disciplinas não contemplam de fato condições para que os discentes/professores em formação desenvolvam um conhecimento crítico para o uso das tecnologias no processo de ensino e aprendizagem. (AVELAR; FREITAS, 2018, p.214)

Diante de tal realidade, surge a nossa proposta da ação de extensão com a intenção de propiciar um espaço na formação de professores de língua inglesa para (re)pensar as práticas digitais articuladas à cibercultura. Menezes de Souza (2011) aponta que esse 'mundo de hoje', em se tratando da globalização, das multiplicidades e da complexidade que o permeiam, "nos obriga a atuar de maneira diferente na nossa sala de aula" (MENEZES DE SOUZA, 2011, p. 279). Escolhemos os games pois, além de multimodais, divertidos e acessíveis em diversos tipos de plataforma, eles estão presentes no dia-a-dia de grande parte da população. De acordo com a pesquisa Game Brasil 2018, 75,5\% dos brasileiros jogam algum tipo de game. A pesquisa mostra ainda que os games são jogados por pessoas de diferentes faixas etárias, desde crianças até os maiores de 54 anos, independente do gênero.

Nessa perspectiva, a ação intitulada "Jogos digitais no ensino de língua inglesa: práticas de (multi)letramentos" foi pensada com os objetivos de 1) preparar os professores para o uso das novas tecnologias por meio do conhecimento prático e teórico fundamentado pelo viés dos (multi)letramentos; 2) estimular o uso do jogo virtual no ensino de línguas.

Optamos por usar os termos game, para tratar de jogos digitais, independente da plataforma ou suporte eletrônico, e o gamer, para tratar dos jogadores desses jogos digitais, independente do nível de proficiência nos jogos pois "os termos são mais específicos, uma vez que jogo e jogador podem se referir a contextos não digitais, tais como futebol, cartas, dentre outros" (AVELAR, 2019). 
Este artigo está organizado em três partes. Na primeira, descrevemos e contextualizamos a ação de extensão. Na segunda parte, são apresentados os encontros e as principais informações acerca de como foram realizados. Na terceira parte, trazemos o referencial teórico associado às nossas observações e às reflexões sobre as experiências relatadas pelos participantes.

\section{A AÇÃO DE EXTENSÃO}

A ação de extensão foi concebida em uma universidade pública situada na cidade de Goiás tendo como público alvo os professores de língua inglesa em formação inicial e continuada. A pesquisa foi aprovada pelo Comitê de Ética e Pesquisa conforme parecer $n^{\circ}$. 3.285.167.

A divulgação foi feita por meios digitais - redes sociais institucionais e via aplicativo de mensagens instantâneas - e também nas salas de aula do curso de Letras. Como a instituição recebe estudantes não só residentes na Cidade de Goiás, como também de municípios vizinhos, e compreendendo a dificuldade de deslocamento fora do horário de aula, optamos por adotar, prioritariamente, o meio digital para realização das inscrições. Para inscrever-se, os interessados deveriam preencher um formulário disponibilizado no Google Forms. O link do formulário também foi disponibilizado por meio de um $Q R$ Code fixado no panfleto de divulgação. A escolha destes instrumentos digitais aconteceu para que os futuros participantes utilizassem tais mecanismos para inscrever-se e para que percebessem que a cibercultura está presente de diversas formas em nosso cotidiano.

O curso teve duração de 60h distribuídas em atividades e encontros que aconteceram intercalando as modalidades presencial e virtual. Os encontros presenciais aconteceram entre os meses de abril e junho, na universidade. As atividades extensionistas eram realizadas às sextas-feiras, no período vespertino.

As discussões e atividades virtuais foram realizadas por meio de um aplicativo de mensagens instantâneas - Whatsapp - e pelo Google Forms. A configuração de encontros virtuais possibilitou que as atividades fossem realizadas conforme a disponibilidade de cada participante, algumas vezes as discussões eram sincrônicas, outras assíncronas. Por se tratar de um recurso multimodal, as interações envolviam mensagens de textos, áudios, imagens e o compartilhamento de outros tipos de arquivos.

Estabeleceu-se um cronograma para quatro encontros presenciais com a proposta de: a) apresentar diferentes games aos participantes; b) fundamentar o ato de jogar a partir de experiências com os games; c) refletir e discutir sobre os games e a educação linguística; d) identificar práticas de linguagem nos games e a 
partir deles; e) relacionar (multi)letramentos e games. A proposta foi propiciar aos professores de língua inglesa em formação inicial e continuada, a partir experiências com os jogos digitais, reflexões pautadas na perspectiva dos multiletramentos (COPE, KALANTZIS, 2000; COSCARELLI, 2016; GEE, 2003; MONTE MOR, 2018; ROJO, MOURA, 2019), na formação de professores (PAIVA, 2013; MENEZES DE SOUZA, 2011) e no uso das tecnologias digitais na educação (LEFFA, 2012; PRENSKY, 2001, 2006).

Para propiciar as experiências com os games, todos os encontros envolveram momentos destinados a joga-los. Foram utilizados um console de $X$-box conectado ao projetor multimídia, alguns notebooks com acesso à internet. $\mathrm{O} X$-box pertencia à pesquisadora, os notebooks e o projetor à Universidade e os smartphones aos participantes.

Foram selecionados diferentes games, em variadas plataformas, para que os participantes pudessem experienciar maneiras diferentes de interagir com os games e com os outros gamers. Alguns games foram jogados durante os encontros presenciais e outros nas atividades online. Assim, os participantes foram convidados a instalar games em seus celulares para jogá-los em outros momentos e compartilhá-los no grupo de Whatsapp. Foram eles: The Legend of Zelda, PacMan, Mortal Kombat, Just Dance, Kinect Adventures,Pokemon, Sim City e Free Fire. Para jogá-los, os participantes interagiam com as múltiplas linguagens e culturas possibilitadas com os games, assim, eles usavam gestos e movimentos para controlar os games, comandos de voz, utilizavam a oralidade e a escrita para se comunicar com os outros gamers, e também realizavam a leitura de gráficos, imagens, sons, dentre outros.

Além dos games selecionados para os encontros, também foram realizados debates baseados em materiais teóricos disponibilizados antes de cada encontro. Essas atividades possibilitaram interação e troca de experiências tanto na perspectiva prática quanto na teórica.

O curso contou com a participação de três professores de língua inglesa em formação inicial - alunos da graduação em Letras - e dois professores de língua inglesa em formação continuada, com idade média entre 19 e 31 anos. Por meio de um questionário inicial identificamos que todos eles se relacionam diariamente com as tecnologias tanto nas atividades de lazer quanto para fins educacionais. Porém, quando questionados acerca de suas experiências tecnológicas na formação de professores foi destacado que a maioria das vezes a tecnologia utilizada era o datashow, no entanto, para reprodução conteúdos via slides. 
Nesse sentido, uma das preocupações da ação de extensão era possibilitar esse espaço para que os participantes se envolvessem com os gamese, a partir daí, refletissem sobre as práticas de linguagem propiciada por eles.

\section{OS ENCONTROS}

Realizamos quatro encontros presenciais e atividades virtuais ao longo de toda a ação. Os encontros presenciais aconteceram em uma sala de reuniões da universidade. A escolha do local foi motivada pelo amplo espaço físico e pela facilidade em organizá-lo tanto em questões de instalação dos aparelhos quanto de organização das mesas e cadeiras, uma vez que por se tratar de uma sala de reuniões está em menor número. Já para as atividades virtuais foi criado um grupo de Whatsapp, aplicativo instantâneo de mensagens, uma vez que todos os participantes já faziam uso deste aplicativo e considerando que ele possibilita o uso de diversos recursos semióticos para comunicação (áudios, gifs, vídeos, texto escrito, imagens, etc.).

O primeiro encontro foi um momento de conversa para nos conhecer, falar sobre as experiências com as tecnologias digitais no cotidiano e nas atividades da graduação e quais as suas experiências com os games. O objetivo aqui era compreender como os participantes se relacionavam com os games e as tecnologias digitais e se, de alguma forma, as experiências digitais estavam inseridas no processo de formação docente destes sujeitos. Também foram esclarecidas as questões éticas da pesquisa e o preenchimento do Termo de consentimento livre e esclarecido.

Iniciamos o segundo encontro com os games. Ao chegar, os participantes encontraram games disponíveis nos notebooks, X-box e Nintendo swich. Assim, todos puderam experimentar games mais clássicos, como o PacMan, à games mais modernos, como Just Dance. A escolha foi feita pensando em fomentar diferentes experiências com games, seus diferentes níveis de complexidade e possibilidades de interação. De modo geral, os participantes se envolveram com os games e entre si. Alguns games causaram mais dificuldade, por se tratar de plataformas às quais não estavam habituados a utilizar, entretanto, os participantes se engajaram para descobrir como jogá-los e a medida em que conseguiam auxiliavam os demais. Houve relatos sobre as sensações vivenciadas e experienciadas, as percepções sobre os games e as alternativas utilizadas para lidar com as dificuldades e, então, dialogamos sobre as práticas de linguagem que emergiram desse processo.

Feitas as reflexões, apresentamos algumas informações sobre a história dos games trazendo aspectos sobre o contexto de surgimento dos jogos eletrônicos, a sua popularização e como eles poderiam se relacionar com a perspectiva do multiletramentos. 
No terceiro encontro, solicitamos que os participantes baixassem o game Sonicno celular e alterassem as configurações de língua para o inglês. Não houve dificuldades para baixá-lo, visto que estão familiarizados com este tipo de procedimento. Houve muita interação durante o jogo, sendo que os participantes discutiam as ações realizadas, trocavam informações sobre o significado de algumas imagens que apareciam durante a partida e orquestravam ideias. Encerrado o game, problematizamos sobre a narrativa e os objetivos dele. Algumas reflexões foram realizadas observando o cenário apresentado no game e as ações realizadas pelos participantes no intutito de compreendê-lo. A discussão foi relevante e levou-nos a refletir sobre a construção de sentido a partir das experiências. Problematizando algumas discussões e após refletir sobre as diferentes modalidades presentes, suscitamos que, para além do game, é possível tratar de questões - a partir dele - com vários temas como tecnologia e preservação ambiental.

Entre o terceiro e quarto encontro, intercalamos uma atividade significativa em que os participantes receberam no grupo de whatsapp a indicação de dois games que deveriam ser jogados durante este intervalo. Além de jogá-los, era necessário enviar prints- que são capturas de imagens da tela de um celular ou computador - que mostrassem esta prática. Ao propor a atividade já havíamos decido qual seriam os games, no entanto, alguns participantes manifestaram com entusiasmo a expectativa de que um deles fosse o Free Fire, por sua popularização e por ter conhecimento de que a maioria de seus alunos o jogam. Assim, encaminhamos a proposta de jogar Free Fire, atendendo as expectativas dos participantes, e SimCity, que é mais intuitivo, por ser simulador, e possibilitar também outras formas de interação.

O quarto encontro foi realizado com a proposta de propiciar um olhar para além dos games. Os participantes jogaram Mortal Kombat intercalando as duplas. Após, dialogamos sobre as experiências de jogar e das relações estabelecidas com os games Free Fire e SimCity - jogados nos dias anteriores - e do Mortal Kombat. As reflexões foram pautadas nas diferentes leituras propiciadas pelos games e nas questões socioculturais emergentes nesses games, tais como gênero, violência, estratégia, dentre outros. Pontuamos que os gamersextrapolam o contexto do game associando-no à realidade sociocultural a qual se inserem, dialogando sobre diferentes questões nos chatsdisponíveis no próprio game, ou em outros suportes, como plataformas de compartilhamento de vídeo (Youtube, Twitch, etc.), nas redes sociais (Instagram, Twitter, Facebook, etc.), blogs e vlogs, fóruns das desenvolvedoras dos games e sites de notícias. 


\section{REFLETINDO...}

Embora o nome do curso de extensão já explicitasse a proposta de falar de games e multiletramentos no ensino de língua inglesa, o fato de trazer os games e reservar momentos para que os participantes jogassem-nos causou espanto e estranhamento. Os primeiros momentos dos encontros eram reservados para jogar e as discussões teóricas eram baseadas nestas experiências associadas aos textos lidos. Uma das participantes relatou que quando viu que iriam jogar teve vontade de não retornar, pois entendia aquele momento como uma perda de tempo e que, a principio, retornou por curiosidade em relação as discussões teóricas. Para os participantes, $\mathrm{o}$ ato de jogar estava, ainda, associado meramente a uma atividade de entretenimento e não à uma atividade sociocultural e prática de linguagem.

A partir do relato dos participantes observamos que ao entrar na sala e encontrar todos aqueles games como parte de uma atividade de formação foi impactante de várias formas, já que, em grande parte de suas experiências o curso aconteceria a partir de leitura de textos e discussões. Apesar disto, os participantes se divertiram, interagiam e se entusiasmaram durante os jogos. Inicialmente, quando questionados sobre como foi experienciar as atividades, remetiam aos conceitos convencionais do ato de jogar tais como vontade de passar de fase e vencer.

A construção de sentidos aconteceu a partir das reflexões críticas a cerca destas experiências que oportunizaram (re)pensar as práticas de linguagem emergentes da relação destes com os games e as possibilidades que os extrapolam. Como apontam Jordão, Jucá e Takaki (2019, p.61), "é importante ensinar e aprender a construir sentidos com os repertórios dos usuários envolvidos nas situações específicas de práticas de linguagem, assim como criar recursos e compartilhá-los no momento de comunicação". Leffa explica que "por ser uma prática social, o videogame propicia oportunidades de prática da língua em situações simuladas e autênticas de uso" (LEFFA et al, 2012, p.226). O autor acrescenta que os games possibilitam inúmeras formas de interação, deste modo seus interagentes poderão participar "não apenas como ouvinte ou leitor, mas como agente, entrando na história, construindo identidades, assumindo avatares, interferindo no enredo e mudando o curso da narrativa" (LEFFA et al, 2012, p.227).

No decorrer dos encontros, simultaneamente às experiências práticas com os games tecemos relações com a prática docente, refletindo sobre a relação horizontal entre professor e aluno, e não mais no professor como detentor de todo o conhecimento. Por várias vezes, os participantes relataram que, no que tange aos games, seus alunos tem domínio do conteúdo e quando são associados às aulas de 
línguas fazem com que os alunos participem e interajam mais. Menezes de Souza (2011, p.289) destaca que enquanto professores não é nosso papel a mera transmissão de conhecimentos, mas que "nós somos as pessoas que vão ensinar para outras pessoas como buscar conhecimentos diferentes, como avaliar a relevância desses conhecimentos diferentes para seus interesses, as suas necessidades".

Um dos desafios desta ação está relacionado ao preconceito e estereótipo negativo dos games. Muitas vezes devido à falta de conhecimento dos games as pessoas tendem a vê-los como prejudiciais ou simplesmente como uma atividade de entretenimento. No entanto, em se tratando de texto, os games apresentam múltiplas possibilidades "significativas, experienciais, sociais e epistemológicas ao mesmo tempo" (SHAFFER at al. 2005, p.105). Percebê-los enquanto prática de multiletramentos possibilitará ao professor de língua inglesa um olhar mais crítico e poderá provocar novas formas de aprender, ensinar, expressar, comunicar e construir sentidos.

As experiências vividas durante a ação de extensão possibilitou a (re)ssignificação dos games para estes participantes que relataram mudanças não só na maneira como compreendiam os games, mas na prática docente. Uma das participantes explanou que passou dar mais atenção aos seus alunos e percebeu o quanto eles aprendem com os games e o quanto têm a ensinar. Outra participante explicou que só conseguiu jogar o Free Fire porque seus alunos a ensinaram e, para isso, eles a inseriram na equipe e instruíram-na sobre a jogabilidade do game. Esse processo de (re)ssignificação foi gradativo e perceptível durante toda a ação de extensão.

\section{ALGUMAS CONSIDERAÇÕES}

Propomos a ação de extensão na formação de professores de língua inglesa, considerando as mudanças nas práticas de linguagem que são propiciadas pelas tecnologias digitais. Entendemos que há mudanças na forma como as pessoas se comunicam, sendo que algumas destas são motivadas pelas multimodalidades presente na cibercultura.

Embora motivados pela afeição à língua inglesa e por reconhecer a importância do universo digital que se insere enquanto prática cultural de grande parte da sociedade, os participantes desta pesquisa receavam do potencial dos gamesenquanto espaço de linguagem. Atribuímos esse receio à falta de experiências com os games e possivelmente pela educação tradicional em relação ao ensino-aprendizagem de línguas. Ferraz e Mattos (2019, p. 239) destacam que muitas características da educação tradicional "já não dão conta de sociedades cada vez mais conectada 
digitalmente, fluidas e em rápida transformação", portanto, urge (re)pensar a formação de professores de línguas propiciando uma educação linguística crítica.

O curso, por sua vez, possibilitou um espaço para a construção de sentidos e (re)significação dos games para estes professores de língua inglesa em formação. Nesta perspectiva, acreditamos que a experiência com os games poderá propiciar aos professores novos olhares, contribuindo para uma formação e reflexões críticas.

\section{REFERÊNCIAS}

AVELAR, Michely Gomes ; FREITAS, Carla Conti de; LOPES, Cristiane Rosa. As tecnologias de informação e comunicação e a formação de professores de língua inglesa. Revista REVELLI: dossiê multiletramentos, tecnologias e educação à distância em tempos atuais, Inhumas, v.10, n.3, p. 174-184, set.2018.

AVELAR, Michely Gomes; FREITAS, Carla Conti de. O uso de jogos digitais como prática de multiletramentos: desafio na formação de professores. In: FREITAS, Carla Conti.; BROSSI, Giuliana C.; SILVA, Valéria Rosa; HERMES JUNIOR, Alcides T. (org.). Diálogos entre a universidade e a escola na [trans]formação de professores de línguas. Anápolis: Editora UEG, p. 209-226, 2018.

AVELAR, Michely Gomes. Game on: experiência com games na formação de professores de língua inglesa. Mestrado (Dissertação). Programa de Pós-Graduação em em Língua, Literatura e Interculturalidade, Universidade Estadual de Goiás, Goiás, 2019.

BEAVIS, Catherine. Game as text, games as action: videogames in the English classroom. Journal of adolescent and adult literacy, v.57, p. 433-439, 2014.

FERRAZ, Daniel; MATTOS, Andrea. Formação de professores de línguas estrangeiras: as contribuições dos letramentos críticos. In: FINARDI, K.; SCHERRE, M.; VIDON, L. (Org.). Língua, discurso e política: Desafios contemporâneos. 1ed. Campinas: Pontes editores, 2019, v. 1, p. 233-253. 
FREITAS, Carla Conti de. Multiletramentos na formação de professores de línguas: das limitações às novas práticas curriculares. Revista Coralina. Cidade de Goiás, v.1, n.1, fev.2019.

LEFFA, Vilson J.; BOHN, Hilário; DAMASCENO, Vanessa D.; MARZARI, Gabriela Q. Quando jogar é aprender: o videogame na sala de aula. Revista Estudos da Linguagem, Belo Horizonte, v. 20, n.1, p. 209-230, 2012.

MENEZES DE SOUZA. Lynn Mario Trindade. O professor de inglês e os letramentos no século XXI: métodos ou ética? In: JORDÃO, Clarissa Menezes; MARTINEZ, Juliana Zeggio; HALU, Regina Célia. Formação desformatada - práticas com professores de língua inglesa. Campinas, SP: Pontes Editores, 2011. p. 279-303.

JORDÃO, Clarissa; JUCÁ, Leina; TAKAKI, Nara. Zooming in and out com professores de inglês. In: NASCIMENTO, Ana Karina de O.; ZACCHI, Vanderlei J. Formação docente em língua inglesa: diferentes perspectivas. Campinas, SP: Mercado de letrs, 2019. p. 55-78,

SHAFFER, David Williamson; SQUIRE, Kurt R.; HALVERSON, Ricard; GEE, James Paul. Video Games and the future of learning. Phi Delta Kappan, oct. 2005. 